\title{
Teaching Quality Evaluation of University Teachers Based on Factor Analysis-an Empirical Research
}

\author{
Peng Yang ${ }^{1, a}$, Ya Tian ${ }^{1, b}$, Na Zhang ${ }^{2, c}$ \\ ${ }^{1}$ Xingtai University, Xingtai, 054001, China \\ ${ }^{2}$ Xingtai Medical College, Xingtai, 054000, China

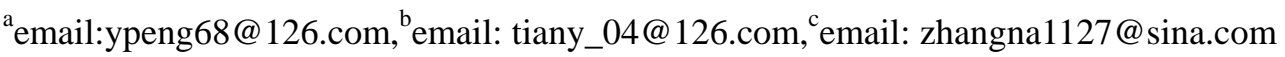

\section{Keywords:teaching quality evaluation; factor analysis; empirical research}

\begin{abstract}
The evaluation of teaching quality is an important work for the universities. Based on the questionnaire survey about teaching quality, we adopt the factor analysis method to synthetically analyze the teaching quality evaluation indexes data, and get every factor scores and the comprehensive evaluation scores, then determine the ranking and the personality diagnosis of each teacher on teaching situation. This paper gives a effective quantitative evaluation methods. It has a great effect on improving the teaching management level and teaching quality.
\end{abstract}

\section{Introduction}

Higher education quality assurance has become a core problem. Teaching quality evaluation of higher education can improve education level and promote the development of universities. A good teaching evaluation can help teachers to know their teaching situation and adjust their teaching methods. At the same time, teaching management departments can master every teacher's teaching quality , and to provide a basis for teacher awards and education reform.

\section{Teaching quality evaluation of university teachers}

(1) Index selection and data collection

We use the method of multivariate statistical analysis to evaluate the teaching quality of Xingtai university teachers, let students score the 14 teachers in a semester. Granting 100 questionnaires, recycling 95 copies, of which 92 valid questionnaires, the effective recovery rate of $92 \%$. Set 12 indicators, as follows show:

$\mathrm{x} 1$ : Use excellent teaching method. $\quad \mathrm{x} 2$ : Pay attention to the quality of the homework.

x3: Teach students thinking and learning method. x4: Let students speak one's mind freely.

x5: Arrange the teaching contents scientifically. $\quad x 6$ : Make the important points stand out.

x7: Be strict with oneself. $\quad$ x8: Seriously lectures, listen to the views with an open mind. x9: Teaching lively and interesting. $x 10$ : Watch new trends in discipline, arouse students' interest. x11: Scientific use of multimedia. $\quad x 12$ : Teaching inspiration.

All indexes are divided into four grades: excellent [90,100], good [80, 90), qualified [60, 80), unqualified $[0,60)$. According to the questionnaires recovered, calculate the mean scores of every index of teachers, and get teaching quality indexes' raw data.

(2) Empirical analysis

Analyze the original data by means of factor analysis method in SPSS software.

Step1: Calculate correlation coefficient matrix of the original data.

Table 1 correlation coefficient matrix

\begin{tabular}{ccccccccccccc}
\hline & $\mathrm{x} 1$ & $\mathrm{x} 2$ & $\mathrm{x} 3$ & $\mathrm{x} 4$ & $\mathrm{x} 5$ & $\mathrm{x} 6$ & $\mathrm{x} 7$ & $\mathrm{x} 8$ & $\mathrm{x} 9$ & $\mathrm{x} 10$ & $\mathrm{x} 11$ & $\mathrm{x} 12$ \\
\hline $\mathrm{x} 1$ & 1 & -0.096 & 0.843 & 0.87 & 0.01 & -0.044 & 0.21 & 0.244 & 0.483 & 0.728 & 0.585 & 0.868 \\
$\mathrm{x} 2$ & -0.096 & 1 & -0.111 & 0.189 & 0.201 & 0.235 & 0.591 & 0.475 & 0.428 & 0.417 & 0.348 & 0.188 \\
$\mathrm{x} 3$ & 0.843 & -0.111 & 1 & 0.835 & -0.009 & -0.114 & 0.042 & 0.079 & 0.315 & 0.7 & 0.322 & 0.854 \\
$\mathrm{x} 4$ & 0.87 & 0.189 & 0.835 & 1 & 0.046 & -0.016 & 0.326 & 0.238 & 0.542 & 0.905 & 0.52 & 0.915 \\
$\mathrm{x} 5$ & 0.01 & 0.201 & -0.009 & 0.046 & 1 & 0.984 & 0.358 & 0.41 & 0.48 & 0.019 & 0.569 & 0.282 \\
\hline
\end{tabular}




\begin{tabular}{ccccccccccccc}
\hline x6 & -0.044 & 0.235 & -0.114 & -0.016 & 0.984 & 1 & 0.366 & 0.4 & 0.476 & -0.038 & 0.579 & 0.219 \\
x7 & 0.21 & 0.591 & 0.042 & 0.326 & 0.358 & 0.366 & 1 & 0.893 & 0.224 & 0.338 & 0.455 & 0.355 \\
x8 & 0.244 & 0.475 & 0.079 & 0.238 & 0.41 & 0.4 & 0.893 & 1 & 0.254 & 0.256 & 0.443 & 0.309 \\
x9 & 0.483 & 0.428 & 0.315 & 0.542 & 0.48 & 0.476 & 0.224 & 0.254 & 1 & 0.558 & 0.798 & 0.546 \\
x10 & 0.728 & 0.417 & 0.7 & 0.905 & 0.019 & -0.038 & 0.338 & 0.256 & 0.558 & 1 & 0.464 & 0.815 \\
x11 & 0.585 & 0.348 & 0.322 & 0.52 & 0.569 & 0.579 & 0.455 & 0.443 & 0.798 & 0.464 & 1 & 0.671 \\
x12 & 0.868 & 0.188 & 0.854 & 0.915 & 0.282 & 0.219 & 0.355 & 0.309 & 0.546 & 0.815 & 0.671 & 1 \\
\hline
\end{tabular}

We get the correlation coefficient matrix as table 1 . We can see that a strong correlation exists between the many indicators. If we directly use the index information to do teaching evaluation, it will affect the reliability of evaluation result.

Step2: Principal component analysis was performed by using the correlation coefficient matrix. We get the eigenvalues and the variance contribution rate of principal components.

Table 2 eigenvalues and variance contribution rate table

\begin{tabular}{|c|c|c|c|c|c|c|c|c|c|}
\hline छี & \multicolumn{3}{|c|}{ Initial Eigenvalues } & \multicolumn{3}{|c|}{$\begin{array}{l}\text { Extraction Sums of Squared } \\
\text { Loadings }\end{array}$} & \multicolumn{3}{|c|}{$\begin{array}{l}\text { Rotation Sums of Squared } \\
\text { Loadings }\end{array}$} \\
\hline हैं & Total & \begin{tabular}{|c|}
$\%$ of \\
Variance
\end{tabular} & \begin{tabular}{|c} 
Cumulative \\
$\%$
\end{tabular} & Total & $\begin{array}{c}\text { \% of } \\
\text { Variance }\end{array}$ & $\begin{array}{c}\text { Cumulative } \\
\%\end{array}$ & Total & $\begin{array}{c}\text { \% of } \\
\text { Variance }\end{array}$ & $\begin{array}{c}\text { Cumulative } \\
\%\end{array}$ \\
\hline 1 & 5.709 & 47.574 & 47.574 & 5.709 & 47.574 & 47.574 & 4.796 & 39.968 & 39.968 \\
\hline 2 & 2.947 & 24.559 & 72.133 & 2.947 & 24.559 & 72.133 & 2.824 & 23.531 & 63.5 \\
\hline 3 & 1.485 & 12.375 & 84.508 & 1.485 & 12.375 & 84.508 & 2.521 & 21.008 & 84.508 \\
\hline 4 & 0.914 & 7.62 & 92.129 & & & & & & \\
\hline 5 & 0.452 & 3.77 & 95.899 & & & & & & \\
\hline 6 & 0.195 & 1.625 & 97.524 & & & & & & \\
\hline 7 & 0.158 & 1.315 & 98.839 & & & & & & \\
\hline 8 & 0.078 & 0.652 & 99.49 & & & & & & \\
\hline 9 & 0.03 & 0.249 & 99.739 & & & & & & \\
\hline 10 & 0.02 & 0.169 & 99.908 & & & & & & \\
\hline 11 & 0.007 & 0.056 & 99.964 & & & & & & \\
\hline 12 & 0.004 & 0.036 & 100 & & & & & & \\
\hline
\end{tabular}

As can be seen from table 2,the cumulative contribution rate of the first three eigenvalue reached $84.508 \%$, which illustrate that the information of the first three public factors accounted for $84 \%$ of the total information. According to the comprehensive analysis,we select three main factors.

Step3: Get the main factor load matrix.

Factor analysis is designed to know the actual meaning of the common factors. But from table 3 we can see that the typical variables of all the common factors is not very obvious, the practical significance of the common factor explain difficultly. So we use the variance maximization orthogonal rotation method to do factor rotation. 
Table 3 component matrix

\begin{tabular}{cccc}
\hline & Component 1 & Component 2 & Component 3 \\
\hline x1 & 0.801 & -0.489 & -0.098 \\
x2 & 0.402 & 0.454 & 0.549 \\
x3 & 0.687 & -0.605 & -0.127 \\
x4 & 0.868 & -0.435 & 0.067 \\
x5 & 0.428 & 0.719 & -0.47 \\
x6 & 0.383 & 0.777 & -0.452 \\
x7 & 0.559 & 0.494 & 0.566 \\
x8 & 0.536 & 0.512 & 0.467 \\
x9 & 0.745 & 0.194 & -0.273 \\
x10 & 0.825 & -0.348 & 0.22 \\
x11 & 0.814 & 0.294 & -0.24 \\
x12 & 0.923 & -0.271 & -0.095 \\
\hline
\end{tabular}

Table 4 rotated component matrix

\begin{tabular}{cccc}
\hline & Component 1 & Component 2 & Component 3 \\
\hline x1 & 0.941 & 0.073 & 0 \\
x2 & 0.04 & 0.112 & 0.809 \\
x3 & 0.916 & -0.031 & -0.125 \\
x4 & 0.956 & 0.031 & 0.182 \\
x5 & -0.034 & 0.944 & 0.168 \\
x6 & -0.105 & 0.953 & 0.192 \\
x7 & 0.145 & 0.192 & 0.905 \\
x8 & 0.12 & 0.258 & 0.829 \\
x9 & 0.515 & 0.607 & 0.185 \\
x10 & 0.862 & -0.028 & 0.325 \\
x11 & 0.513 & 0.68 & 0.287 \\
x12 & 0.916 & 0.264 & 0.16 \\
\hline
\end{tabular}

According to the factor loading matrix after rotation,we can see from table 4:

The $\mathrm{x} 1, \mathrm{x} 3, \mathrm{x} 4, \mathrm{x} 9, \mathrm{x} 10, \mathrm{x} 11, \mathrm{x} 12$ load is large of the first main factor. These indicators reflect that teachers should make good use of teaching methods, to train students' learning and thinking ability, so the thinking and analysis ability of students was improved greatly. So the first main factor can be called students benefit factor, play a key role in the teaching quality evaluation.

The $x 5$, x6 load is large of the second factor. The two indicators reflect the teachers' teaching ability, so the second factor can be called teaching ability factor.

The $\mathrm{x} 2, \mathrm{x} 7, \mathrm{x} 8$ load is high of third main factors. These indicators reflect the ethics of teachers, so three main factor can be called the teacher ethics factor.

Further we get the factor scores coefficient matrix as table 5:

Table 5 factor scores coefficient matrix

\begin{tabular}{cccc|cccc}
\hline & Component 1 & Component 2 & Component 3 & & Component 1 & Component 2 & Component 3 \\
\hline x1 & 0.213 & -0.008 & -0.078 & x7 & -0.036 & -0.093 & 0.416 \\
x2 & -0.051 & -0.106 & 0.389 & x8 & -0.04 & -0.048 & 0.366 \\
x3 & 0.221 & -0.03 & -0.12 & x9 & 0.079 & 0.214 & -0.056 \\
x4 & 0.206 & -0.062 & 0.022 & x10 & 0.178 & -0.112 & 0.113 \\
x5 & -0.06 & 0.391 & -0.092 & x11 & 0.069 & 0.226 & -0.018 \\
x6 & -0.079 & 0.394 & -0.076 & x12 & 0.189 & 0.047 & -0.031 \\
\hline
\end{tabular}

Step4: Get the comprehensive evaluation scores.

According to the factor scores, put the original index values into the factor scores model, obtains teacher's main factor scores of $\mathrm{Fi}(\mathrm{i}=1,2,3)$, then regard the variance contribution rate of each main factor as the weight, calculates the comprehensive scores of each teachers' teaching effect. $\mathrm{F}=(0.39968 \mathrm{~F} 1+0.23531 \mathrm{~F} 2+0.21008 \mathrm{~F} 3)$. At last get every teacher's main factor scores and teaching quality comprehensive scores as table 6.

Table 6 results of comprehensive evaluation

\begin{tabular}{cccccc|cccccc}
\hline teacher & F1 & F2 & F3 & F & ranking & teacher & F1 & F2 & F3 & F & ranking \\
\hline 1 & 1.724 & -1.390 & -1.083 & 0.134 & 5 & 8 & -1.048 & 0.029 & 0.934 & -0.216 & 9 \\
2 & 0.710 & -1.594 & 0.646 & 0.044 & 6 & 9 & 0.428 & 1.777 & -1.374 & 0.301 & 4 \\
3 & 0.017 & 0.346 & -1.669 & -0.262 & 10 & 10 & -1.055 & -0.329 & 0.426 & -0.409 & 11 \\
4 & 0.431 & 0.699 & 0.446 & 0.430 & 3 & 11 & 1.054 & 1.367 & 0.329 & 0.812 & 2 \\
5 & 0.402 & -0.829 & -0.105 & -0.057 & 8 & 12 & -1.704 & 0.262 & -0.984 & -0.826 & 14 \\
6 & 1.032 & 0.903 & 1.719 & 0.986 & 1 & 13 & -0.614 & 0.125 & 1.152 & 0.026 & 7 \\
7 & -1.123 & -0.323 & -0.118 & -0.550 & 13 & 14 & -0.253 & -1.044 & -0.318 & -0.414 & 12 \\
\hline
\end{tabular}




\section{Results analysis of teaching quality evaluation}

(1) Comprehensive ranking

We get the comprehensive ranking from table 6 , that is $[6,11,4,9,1,2,13,5,8,3,10,14,7,12]$. The sixth teacher ranks first, and he is worth other teachers learning; the twelfth teacher are the final ranking, the students benefit factor and teacher ethics factor have a great gap with others . We see that the first principal factor scores result in the top ranking in comprehensive score ranking, so teachers who want to improve teaching quality must work hard in the $x 1, x 3, x 4, x 9, x 10, x 11, x 12$ aspects. They should use the good teaching methods, such as heuristic teaching, multimedia aided teaching, to make students master learning method, to let the students get the maximum profit.

(2) Personality diagnosis

We compare every teacher with the main factor scores in teaching methods, teaching content, teaching attitude, teaching basic skills. Teachers can find their weaknesses. For example, the first teacher's comprehensive score ranking fifth, his students benefit factor score is 1.724, while the teaching ability factor score is -1.390 and the ethics factor score is -1.083 . The first teacher's students benefit factor is higher, students will improve a lot, but the teaching ability factor and the ethics factor lies below the average. The improvement in the future should focus on the two aspects.

\section{Conclusion}

We use factor analysis method in the evaluation of teaching quality. Base on the multiple index comprehensive evaluation system, translate the more related variables into a few independent factors, and evaluate teaching quality with the comprehensive factors. It effectively eliminates the effects of the relevant indicators, simplifying the evaluation system, and the evaluation result is objective and reliable strongly. At the same time, the result has the whole comprehensive ranking and the individual targeted analysis. Both for the teaching assessment, and for the improvement of personal teaching level, it has great practical significance.

\section{References}

[1]Ying Chen. Student Evaluation of Teaching Effectiveness: An assessment of student perception and motivation[J]. Assessment \& Evaluation in Higher Education, 2003.

[2]Diping Zhang, Ming LI. Application of multivariate statistical analysis to teaching quality evaluation[J]. Zhejiang University of Science and Technology. Vol. 14 No. 1, Mar. 2002

[3]Simpson R.D. Uses and misuses of student evaluations of teaching effectiveness[J]. Innovative Higher Education, 1995.

[4]Dunrong Bie, Fan Meng. On student evaluation of teaching and improvement of the teaching quality assurance system at higher education institutions[J].Chinese Education \& Society, 2009,04.

[5]Guoan Li, Weihua Li. Application of factor analysis method in the teaching effect evaluation in the course[J]. Mathematics in practice and theory, 2006.

[6]Gerun Huang,Wei Sheng. A statistical method for the evaluation of the teaching quality[J]. Application of probability and statistics, 1996. 